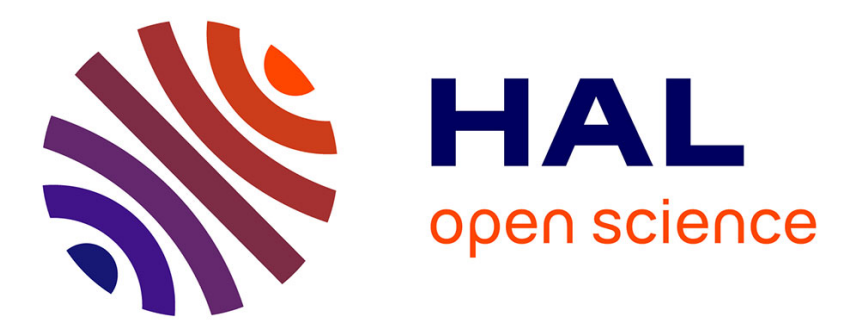

\title{
Developing a Reflective Mind: From Core Metacognition to Explicit Self-Reflection
}

Louise Goupil, Sid Kouider

\section{To cite this version:}

Louise Goupil, Sid Kouider. Developing a Reflective Mind: From Core Metacognition to Explicit Self-Reflection. Current Directions in Psychological Science, 2019, 28 (4), pp.403-408. 10.1177/0963721419848672 . hal-03015918

\section{HAL Id: hal-03015918 \\ https://hal.science/hal-03015918}

Submitted on 20 Nov 2020

HAL is a multi-disciplinary open access archive for the deposit and dissemination of scientific research documents, whether they are published or not. The documents may come from teaching and research institutions in France or abroad, or from public or private research centers.
L'archive ouverte pluridisciplinaire HAL, est destinée au dépôt et à la diffusion de documents scientifiques de niveau recherche, publiés ou non, émanant des établissements d'enseignement et de recherche français ou étrangers, des laboratoires publics ou privés. 


\title{
Developing a Reflective Mind: From Core Metacognition to Explicit Self-Reflection
}

Current Directions in Psychological Science

1-6

(C) The Author(s) 2019

Article reuse guidelines: sagepub.com/journals-permissions DOI: $10.1177 / 0963721419848672$ www.psychologicalscience.org/CDPS (SAGE

\author{
Louise Goupil $^{1}$ and Sid Kouider ${ }^{2}$ \\ ${ }^{1}$ Science and Technology of Music and Sound, Unités Mixtes de Recherche 9912, Centre National \\ de la Recherche Scientifique/Institut de Recherche et de Coordination en Acoustique/Musique, \\ Paris, France, and ${ }^{2}$ Brain and Consciousness Group, Département d'Études Cognitives, \\ École Normale Supérieure, Centre National de la Recherche Scientifique, École des Hautes \\ Études en Sciences Sociales, PSL Research University
}

\begin{abstract}
Metacognition is the ability to monitor and control cognition. Because young children often provide inaccurate metacognitive judgments when prompted to do so verbally, it has long been assumed that this ability does not develop until late childhood. This claim is now challenged by new studies using nonverbal paradigms and revealing that basic forms of metacognition — such as the ability to estimate decision confidence or to monitor errors-are present even in preverbal infants. This new line of evidence suggests that young children adapt to their environment not only by considering their physical and social surroundings but also by reflecting on their own cognitive states.
\end{abstract}

\section{Keywords}

metacognition, confidence, error monitoring, development, self-reflection

Metacognition is our ability to reflect on our own mental representations to regulate cognition and optimize learning. Given metacognition's importance for education, its development has been studied intensively since the 1970s. For several decades, on the basis of studies that primarily relied on verbal reports, researchers argued that young children have poor and inefficient selfreflective abilities (for reviews, see Flavell, 2000; Sodian, Thoermer, Kristen, \& Perst, 2012). Yet it now appears that young children's limitations largely reflect an inability to provide accurate metacognitive reports rather than an absence of metacognition per se. Indeed, a new line of investigation relying on nonverbal paradigms and focusing on error monitoring (i.e., detecting one's own mistake) and decision confidence (i.e., estimating the probability that a choice was correct) has revealed that even preverbal infants engage in rudimentary forms of metacognition. In this article, we briefly review this burgeoning literature before proposing a framework that integrates recent findings with more traditional research documenting a slow and effortful development of explicit aspects of metacognition.

\section{Early Forms of Metacognition}

Over the last decade, several approaches have been elaborated to examine the development of metacognition without relying on verbal reports. A first approach revealed that when 3- to 5-year-olds are trained to use a nonverbal confidence scale depicting pictures of a confident or a doubtful peer, they quickly learn how to use it appropriately (Ghetti, Hembacher, \& Coughlin, 2013). That is, they provide higher confidence judgments for correct compared with incorrect responses, thereby displaying metacognitive sensitivity (i.e., accurate evaluations of their performances). One limit of this approach, however, is that nonverbal confidence scales still require an understanding of the concept of confidence: To use them appropriately, children must understand how the symbolic representations depicted by the scale map onto their internal states of uncertainty. Thus, this type of measure cannot be extended to test younger children, who cannot be verbally instructed on how to use such a scale.

Consequently, a second approach consisted of adapting behavioral methods stemming from the animal literature. In particular, in the opt-out paradigm (Hampton,

Corresponding Authors:

Louise Goupil, Institut de Recherche et Coordination en Acoustique et Musique, 1 Place Igor Stravinsky, 75001, Paris, France

E-mail: louise.goupil@ircam.fr

Sid Kouider, École Normale Supérieure, Laboratoire de Sciences Cognitives et Pscyholinguistique, Pavillon Jardin, 29 Rue d'Ulm, 75005, Paris, France

E-mail: sid.kouider@ens.fr 
2009), participants are presented with a binary choice, either in a condition in which they have no option but to choose by themselves (forced choice) or in a condition in which they are also given the additional option to avoid responding (i.e., opt out). The rationale behind this paradigm is that if participants are able to monitor their own uncertainty, they should opt out specifically when they are uncertain, and thereby avoid making errors in choosing between the two alternatives. In such a task, 3-year-olds (Balcomb \& Gerken, 2008) and even 20-month-olds, who cannot yet verbally communicate their knowledge states (Goupil, Romand-Monnier, \& Kouider, 2016), have been found to opt out appropriately to avoid errors. In one of these experiments, 20-month-old toddlers had to remember the location of a toy hidden for variable durations (to induce several levels of difficulty) before pointing to indicate where they wanted to recover it (Goupil et al., 2016). Although toddlers in a control group had no option other than to decide by themselves, toddlers in a test group were given the extra option of asking their caregiver for help through nonverbal communication. In this test group, only two training trials allowed toddlers to understand that they could withhold their response when feeling uncertain and ask their caregiver for help instead. Toddlers opted out not only to avoid difficult choices but also to avoid making errors irrespective of task difficulty; even in easy trials, toddlers in the test group made fewer errors than toddlers in the control group. Importantly, the rate of correct choices remained the same across the two groups, demonstrating that the toddlers opted out specifically to avoid making errors. Overall, the results revealed that toddlers were not merely responding on the basis of risk avoidance (e.g., escaping from difficult choices) or other first-order (i.e., cognitive) mechanisms. Rather, the results showed that children appraised their probability of success (i.e., asked for help when confidence was low; see Goupil et al., 2016, for further information).

Converging evidence comes from a third approach elaborated by comparative psychologists to measure metacognition while ruling out first-order interpretations: postdecision wagering. In such a task, 5-year-old children place higher bets on correct compared with incorrect responses (Vo, Li, Kornell, Pouget, \& Cantlon, 2014). Recently, we used a totally nonverbal variant of this paradigm to demonstrate that preverbal infants also display such metacognitive sensitivity (Goupil \& Kouider, 2016). Infants made a decision (18-month-olds pointed to indicate the location of a hidden toy; 12-month-olds gazed toward the location of a briefly presented face) followed by a measure of postdecision persistence. This measure relies on the fact that one will wait longer for a reward if one thinks that one's response was correct; it has proven to be a reliable proxy for decision confidence in rats and chimpanzees (Beran et al., 2015; Lak et al., 2014). Infants persisted more after making a correct compared with an incorrect decision. Importantly, they did so in the total absence of external feedback on their performance. Further, their persistence did not vary with stimulus or task properties (i.e., memorization delay for 18-month-olds; duration of the masked-face presentation for 12-montholds), but rather constituted a characteristic pattern in which confidence decreased with difficulty for correct judgments but increased for errors (Lak et al., 2014). This suggests that infants' postdecision persistence does not simply reflect properties of external events (e.g., that the face was presented for $100 \mathrm{~ms}$ vs. $300 \mathrm{~ms}$ ), but rather is contingent on the accuracy of their own decisions and reflects a subjective evaluation of performance (see Goupil \& Kouider, 2016).

One might still argue that it remains debatable whether postdecision persistence unambiguously reflects second-order (i.e., metacognitive) computations (Fleming \& Daw, 2017) and that, ultimately, it may be difficult to make conclusions about this issue on the basis of behavioral data alone. Fortunately, a fourth approach using neuroimaging provides more decisive evidence, as it allows researchers to dissociate brain areas associated with metacognitive versus cognitive processes. Regarding confidence, experiments with both rats and monkeys revealed that pharmacological inactivation of specific prefrontal areas impairs metacognitive sensitivity while sparing perceptual decisions (Lak et al., 2014; Miyamoto et al., 2017). Similarly, metacognition causally involves the prefrontal cortex in human adults (Fleming \& Dolan, 2012), and decision confidence is automatically encoded in the ventromedial prefrontal cortex even when no reports are required from the participants (Lebreton, Abitbol, Daunizeau, \& Pessiglione, 2015). The metacognitive system supporting error monitoring also elicits characteristic neural activity originating in the anterior cingulate cortex and reflected in an electroencephalographic potential called the error-related negativity (ERN). This component is thought to reflect a second-order, postdecisional mechanism signaling a mismatch between a just-made (incorrect) decision and the choice that should have been made on the basis of the available evidence (Charles, King, \& Dehaene, 2014).

Consistent with the idea that core metacognition emerges early in development, studies have shown that some of these key prefrontal structures are already functional in infancy (Dehaene-Lambertz \& Spelke, 2015; Goupil \& Kouider, 2016). Although unfortunately no study to date has measured neural markers of decision confidence in young children, a few studies have shown that the mechanisms of error monitoring subtended by the anterior cingulate cortex are already 
functional (Tamnes, Walhovd, Torstveit, Sells, \& Fjell, 2013). For instance, we recently found that following perceptual decisions, infants as young as 12 months of age display an ERN component after making an incorrect choice (Goupil \& Kouider, 2016).

\section{Core Metacognition}

The evidence reviewed above suggests that human infants are already endowed with rudimentary forms of metacognition. Several lines of research suggest that these abilities primarily rely on a phylogenetically ancient metacognitive system that is not strictly tied to explicit reports. Indeed, as mentioned above, confidence and error monitoring are present in several other species, including rats and monkeys (Hampton, 2009). Furthermore, neuroimaging and computational-modeling studies in human adults have revealed that confidence and error monitoring can be reduced to simple computational mechanisms (Fleming \& Daw, 2017; Yeung \& Summerfield, 2012) and can automatically induce selfregulation even when they are not introspectively accessed (Logan \& Crump, 2010; Nieuwenhuis, Ridderinkhof, Blom, Band, \& Kok, 2001). Consequently, modern frameworks emphasize the fact that metacognition does not reduce to its explicit manifestations and stress the importance of implicit forms of self-monitoring and regulation (Proust, 2012; Shea et al., 2014).

Building on these views, we here propose that starting in the first years of life, humans are already endowed with a system of core metacognition allowing them to automatically evaluate and regulate their own cognition. Core metacognition is complementary to other core systems that evolved to fulfill a dedicated function (e.g., representing objects) and on which flexible and explicit capacities build later in development (Carey, 2009; Spelke \& Kinzler, 2007). Whereas other core systems represent properties of the external world, core metacognition specifically evolved to enable the monitoring of internal cognitive states, allowing endogenous engagement in self-regulation. Specifically, core metacognition encompasses any mechanism whereby a firstorder (cognitive) representation (e.g., a belief) is assessed through a second-order (metacognitive) process that evaluates its quality (e.g., the likelihood that the belief is correct given the sensory evidence) without necessarily reaching awareness or being represented explicitly. Importantly, core metacognition is not simply equivalent to cognitive control: It concerns processes that use metacognitive representations (i.e., representations that contain some information about the properties of an underlying cognitive representation; e.g., the reliability of a belief) for self-regulation (for more details, see Shea et al., 2014; for an alternative position on this issue, see Carruthers, 2009). Such a system would be present not only in humans but also in other animals whenever their neural architecture implements second-order structures evaluating first-order representations computed in sensorimotor and other associative areas.

As with other core systems, core metacognition can be considered an innate component relying on the maturation of dedicated brain structures that were shaped by evolution to constrain and optimize our representational space. However, the emergence of core metacognition is certainly protracted compared with other core systems, such as naive physics. Indeed, whereas sensory systems develop rapidly over the first year of life, the prefrontal cortex shows a dramatic increase in synaptic density and long-range connectivity only by the end of the first year (Dehaene-Lambertz \& Spelke, 2015) and substantially matures until adolescence (Lebel, Walker, Leemans, Phillips, \& Beaulieu, 2008). Thus, although the structures that support core metacognition are already functional during the first years of life, they remain largely immature and undergo substantial development throughout childhood. So far, the youngest age at which core metacognition has been observed is 12 months (Goupil \& Kouider, 2016). Whether the maturation of the prefrontal cortex and its long-range connections are sufficient to support metacognition in infants below 1 year of age remains an open question.

\section{Signature Limits of Core Metacognition}

If core metacognition emerges early, why does selfreflection appear so limited and unreliable until much later in childhood, as evidenced by decades of research in developmental psychology? As mentioned above, a first developmental constraint concerns the maturation of the prefrontal areas supporting core metacognition that undergo substantial maturation during childhood. But beyond this slow maturation, the core metacognitive system presents several intrinsic limitations. Below, we characterize these restrictions and detail how the core system interacts with the late-developing system of explicit metacognition.

Core systems are defined not only by a dedicated function but also by distinctive signature limits (e.g., the core system dedicated to object representations is limited to a set size of four; Carey, 2009). A first signature limit of core metacognition is that it is restricted to the evaluation of simple perceptual and value-based decisions. Even human adults tend to shift to inferential, heuristic strategies relying on the interpretation of cues (e.g., response times) - as opposed to relying on optimal metacognitive computations-to evaluate complex decisions and reasoning (Ackerman \& Thompson, 2017). 
A second and perhaps more important limitation of core metacognition is that, in and of itself, it is not sufficient to enable a crucial aspect of human metacognition: the ability to share metacognitive representations with other people (Shea et al., 2014). This latter capacity relies on explicit metacognition, a heterogeneous system that supports the exploitation of consciously accessed metacognitive representations. Decades of developmental research suggest that this system requires the development of several additional abilities (Flavell, 2000; Sodian et al., 2012) that progressively come together to enable children to engage in explicit metacognition and provide accurate metacognitive reports.

First, the ability to focus on metacognitive monitoring and inhibit the use of irrelevant information when providing self-reports is limited in children. Their inaccurate reports reflect an inability to select relevant sources of information (e.g., error signals) while inhibiting inappropriate ones (e.g., desires to succeed). This often results in a "liberal" metacognitive bias with a high propensity to give affirmative (e.g., "Yes I know") responses (i.e., overconfidence; Butterfield, Nelson, \& Peck, 1988; Lipowski, Merriman, \& Dunlosky, 2013). Importantly, this bias is also often observed in human adults (Dunlosky \& Metcalfe, 2009). Children still lack the executive functions necessary to inhibit such prepotent responses and provide accurate metacognitive reports. Indeed, executive functions, and in particular inhibitory control, do not consistently drive behavior before 4 years of age and continue developing until late childhood (Posner, Rothbart, Sheese, \& Voelker, 2014; see also Roebers, 2017, for more details on this issue).

Another developmental constraint concerns the ability to shift from an implicit to an explicit mode of processing. The latter implies directing attention toward metacognitive representations in order to globally broadcast them, thereby rendering them conscious and reportable (Dehaene, Lau, \& Kouider, 2017). To illustrate this contrast between implicit and explicit metacognition, we can return to the neural signatures of error monitoring mentioned above. Although neural markers of implicit error monitoring are observable in the anterior cingulate cortex following incorrect responses and are reflected in the ERN component regardless of introspective access to the error, conscious error detection elicits broader activations in a frontoparietal network that are reflected in a later component called the error-related positivity (Yeung \& Summerfield, 2012). This pattern is similar to what is found for conscious versus unconscious perceptual processes in adults and infants, as the former generally involves early responses that are restricted in time and space whereas the latter evokes late, long-lasting, and widespread activations (Dehaene et al., 2017; Kouider et al.,
2013). Taken together, these data suggest that consciously accessing metacognitive representations involves additional neural processes entailing their global broadcasting. Given that the mechanisms enabling conscious access are already in place during the first year of life (Kouider et al., 2013), it is plausible that, even in infancy, metacognitive representations eventually become conscious when they represent a very strong signal (e.g., when a decision differs greatly from the option favored by sensory evidence). Yet it is also probable that, initially, metacognitive representations remain for the most part unconscious, either because their representational content remains too weak to capture attention or because they are overwritten by stronger alternative signals (e.g., external feedback, desires to succeed).

Finally, beyond executive functions and conscious access, language and culture play a crucial role in building the late-developing system (Flavell, 2000; Sodian et al., 2012). Interactions with caregivers shape and normalize explicit aspects of metacognition (Roebers, 2017; Schneider, 2008), and cultural norms deeply modulate individual strategies when giving self-reports (Ma et al., 2014). Learning a set of linguistic expressions that are efficient to share metacognitive representations in one's own culture is a challenge, as shown by the fact that the acquisition of cognitive-state vocabulary lags behind the acquisition of other lexicons (Bretherton \& Beeghly, 1982) and that even in human adults, efficient communication of confidence depends on linguistic convergence (Fusaroli et al., 2012). Thus, whereas core metacognition is likely to be an innate module evolved through natural selection (like other core systems; Carey, 2009), the emergence of explicit metacognition is largely constrained by the development of higher-order cognitive functions and culturally situated learning.

\section{Conclusion}

We suggest that a core system of metacognition appears very early in development, whereas explicit and humanspecific forms of metacognition slowly emerge to progressively allow children to communicate their metacognitive representations to others. In the field of mind reading, distinctions between implicit and explicit processes have also been used to account for the finding that young children's spontaneous behaviors reveal a sensitivity to other people's beliefs years before they manage to pass explicit false-belief tasks (Low \& Perner, 2012), and similar arguments have been made regarding empathy (Heyes, 2018). How are these two aspects of mind reading and empathy related to the two metacognitive systems? Some evidence suggests that explicit mind reading and metacognition develop together (Flavell, 2000; Lockl \& 
Schneider, 2007), but little empirical data are available regarding implicit aspects. A stimulating avenue for future research will thus be to examine the relationships between these constructs while considering the fact that they cannot be reduced to their explicit manifestations. Another promising avenue for future research will be to examine the potential involvement of metacognition in early learning. Metacognition is a privileged tool to optimally acquire new information, as it allows organisms to assess their own knowledge states and flexibly adapt their strategies to learn optimally in the absence of external feedback (Guggenmos, Wilbertz, Hebart, \& Sterzer, 2016). At the earliest stages of development, when everything remains to be learned, this ability might be one of the key ingredients that allow young children to learn actively and optimally.

\section{Recommended Reading}

Goupil, L., \& Kouider, S. (2016). (See References). An empirical article revealing that core metacognitive mechanisms are already present in 12- and 18-month-old infants.

Proust, J. (2012). (See References). An opinion piece discussing the possibility that metacognition does not reduce to its explicit manifestations.

Shea, N., Boldt, A., Bang, D., Yeung, N., Heyes, C., \& Frith, C. D. (2014). (See References). An opinion article arguing that whereas implicit metacognition is shared with several animal species and serves functions at the subpersonal level, explicit metacognition has evolved to fulfill a social function.

Sodian, B., Thoermer, C., Kristen, S., \& Perst, H. (2012). (See References). A review on the development of metacognition in young children.

\section{Action Editor}

Randall W. Engle served as action editor for this article.

\section{Acknowledgments}

We thank J. Sackur and J. Proust for discussions on the manuscript.

\section{Declaration of Conflicting Interests}

The author(s) declared that there were no conflicts of interest with respect to the authorship or the publication of this article.

\section{Funding}

This research was supported by funding from the Agence Nationale de la Recherche (ANR-17-EURE-0017) and from the European Research Council to S. Kouider (METAWARE project).

\section{References}

Ackerman, R., \& Thompson, V. A. (2017). Meta-reasoning: Monitoring and control of thinking and reasoning. Trends in Cognitive Sciences, 21, 607-617.
Balcomb, F. K., \& Gerken, L. (2008). Three-year-old children can access their own memory to guide responses on a visual matching task. Developmental Science, 11, 750-760.

Beran, M. J., Perdue, B. M., Futch, S. E., Smith, J. D., Evans, T. A., \& Parrish, A. E. (2015). Go when you know: Chimpanzees' confidence movements reflect their responses in a computerized memory task. Cognition, 142, 236-246.

Bretherton, I., \& Beeghly, M. (1982). Talking about internal states: The acquisition of an explicit theory of mind. Developmental Psychology, 18, 906-921.

Butterfield, E. C., Nelson, T. O., \& Peck, V. (1988). Developmental aspects of the feeling of knowing. Developmental Psycho$\log y, 24,654-663$.

Carey, S. (2009). The origin of concepts. Oxford, England: Oxford University Press.

Carruthers, P. (2009). Mindreading underlies metacognition. Behavioral \& Brain Sciences, 32, 164-182.

Charles, L., King, J.-R., \& Dehaene, S. (2014). Decoding the dynamics of action, intention, and error detection for conscious and subliminal stimuli. The Journal of Neuroscience, 34, 1158-1170.

Dehaene, S., Lau, H., \& Kouider, S. (2017). What is consciousness, and could machines have it? Science, 358, 486-492.

Dehaene-Lambertz, G., \& Spelke, E. S. S. (2015). The infancy of the human brain. Neuron, 88, 93-109.

Dunlosky, J., \& Metcalfe, J. (2009). Metacognition. Thousand Oaks, CA: SAGE.

Flavell, J. H. (2000). Development of children's knowledge about the mental world. International Journal of Behavioral Development, 24, 15-23.

Fleming, S. M., \& Daw, N. D. (2017). Self-evaluation of decision-making: A general Bayesian framework for metacognitive computation. Psychological Review, 124, 91-114.

Fleming, S. M., \& Dolan, R. J. (2012). The neural basis of metacognitive ability. Philosophical Transactions of the Royal Society B: Biological Sciences, 367, 1338-1349.

Fusaroli, R., Bahrami, B., Olsen, K., Roepstorff, A., Rees, G., Frith, C., \& Tylén, K. (2012). Coming to terms: Quantifying the benefits of linguistic coordination. Psychological Science, 23, 931-939.

Ghetti, S., Hembacher, E., \& Coughlin, C. A. (2013). Feeling uncertain and acting on it during the preschool years: A metacognitive approach. Child Development Perspectives, 7, 160-165.

Goupil, L., \& Kouider, S. (2016). Behavioral and neural indices of metacognitive sensitivity in preverbal infants. Current Biology, 26, 3038-3045.

Goupil, L., Romand-Monnier, M., \& Kouider, S. (2016). Infants ask for help when they know they don't know. Proceedings of the National Academy of Sciences, USA, 113, 3492-3496.

Guggenmos, M., Wilbertz, G., Hebart, M. N., \& Sterzer, P. (2016). Mesolimbic confidence signals guide perceptual learning in the absence of external feedback. eLife, 5, Article e13388. doi:10.7554/eLife.13388.001

Hampton, R. R. (2009). Multiple demonstrations of metacognition in nonhumans: Converging evidence or multiple mechanisms? Comparative Cognition Behavior Reviews, 4, 17-28. 
Heyes, C. (2018). Empathy is not in our genes. Neuroscience and Biobehavioral Reviews, 95, 499-507.

Kouider, S., Stahlhut, C., Gelskov, S. V., Barbosa, L. S., Dutat, M., de Gardelle, V., . . . Dehaene-Lambertz, G. (2013). A neural marker of perceptual consciousness in infants. Science, 340, 376-380.

Lak, A., Costa, G. M., Romberg, E., Koulakov, A. A., Mainen, Z. F., \& Kepecs, A. (2014). Orbitofrontal cortex is required for optimal waiting based on decision confidence. Neuron, 84, 190-201.

Lebel, C., Walker, L., Leemans, A., Phillips, L., \& Beaulieu, C. (2008). Microstructural maturation of the human brain from childhood to adulthood. NeuroImage, 40, 1044-1055.

Lebreton, M., Abitbol, R., Daunizeau, J., \& Pessiglione, M. (2015). Automatic integration of confidence in the brain valuation signal. Nature Neuroscience, 18, 1159-1167.

Lipowski, S. L., Merriman, W. E., \& Dunlosky, J. (2013). Preschoolers can make highly accurate judgments of learning. Developmental Psychology, 49, 1505-1516.

Lockl, K., \& Schneider, W. (2007). Knowledge about the mind: Links between theory of mind and later metamemory. Child Development, 78, 148-167.

Logan, G. D., \& Crump, M. J. C. (2010). Cognitive illusions of authorship reveal hierarchical error detection in skilled typists. Science, 330, 683-686.

Low, J., \& Perner, J. (2012). Implicit and explicit theory of mind: State of the art. The British Journal of Developmental Psychology, 30, 1-13.

Ma, Y., Bang, D., Wang, C., Allen, M., Frith, C., Roepstorff, A., \& Han, S. (2014). Sociocultural patterning of neural activity during self-reflection. Social Cognitive and Affective Neuroscience, 9, 73-80.

Miyamoto, K., Osada, T., Setsuie, R., Takeda, M., Tamura, K., Adachi, Y., \& Miyashita, Y. (2017). Causal neural network of metamemory for retrospection in primates. Science, 355, 188-193.

Nieuwenhuis, S., Ridderinkhof, K. R., Blom, J., Band, G. P., \& Kok, A. (2001). Error-related brain potentials are differentially related to awareness of response errors:
Evidence from an antisaccade task. Psychophysiology, 38, 752-760.

Posner, M. I., Rothbart, M. K., Sheese, B. E., \& Voelker, P. (2014). Developing attention: Behavioral and brain mechanisms. Advances in Neuroscience, 2014, Article 405094. doi:10.1155/2014/405094

Proust, J. (2012). Metacognition and mindreading: One or two functions? In M. J. Beran, J. L. Brandl, J. Perner, \& J. Proust (Eds.), Foundations of metacognition (pp. 234-251). Oxford, England: Oxford University Press.

Roebers, C. M. (2017). Executive function and metacognition: Towards a unifying framework of cognitive selfregulation. Developmental Review, 45, 31-51.

Schneider, W. (2008). The development of metacognitive knowledge in children and adolescents: Major trends and implications for education. Mind, Brain, and Education, 2, 114-121.

Shea, N., Boldt, A., Bang, D., Yeung, N., Heyes, C., \& Frith, C. D. (2014). Supra-personal cognitive control and metacognition. Trends in Cognitive Sciences, 18, 186-193.

Sodian, B., Thoermer, C., Kristen, S., \& Perst, H. (2012). Metacognition in infants and young children. In M. J. Beran, J. L. Brandl, J. Perner, \& J. Proust (Eds.), Foundations of metacognition (pp. 119-133). Oxford, England: Oxford University Press.

Spelke, E. S., \& Kinzler, K. D. (2007). Core knowledge. Developmental Science, 10, 89-96.

Tamnes, C. K., Walhovd, K. B., Torstveit, M., Sells, V. T., \& Fjell, A. M. (2013). Performance monitoring in children and adolescents: A review of developmental changes in the error-related negativity and brain maturation. Developmental Cognitive Neuroscience, 6, 1-13.

Vo, V. A., Li, R., Kornell, N., Pouget, A., \& Cantlon, J. F. (2014). Young children bet on their numerical skills: Metacognition in the numerical domain. Psychological Science, 25, 1712-1721.

Yeung, N., \& Summerfield, C. (2012). Metacognition in human decision-making: Confidence and error monitoring. Philosophical Transactions of the Royal Society B: Biological Sciences, 367, 1310-1321. 